\title{
Living with satisfactory vision and no comorbidity 28 years after bilateral retinoblastoma: a case report and mini literature review
}

\author{
Evita Evangelia Christou 1 (D), Ioannis Georgiou ${ }^{2,3}$, Charilaos Kostoulas ${ }^{3}$, Georgios Batsos ${ }^{4}$, Eleni Christodoulou ${ }^{4}$, \\ Maria Stefaniotou ${ }^{4}$ \\ ${ }^{1}$ Department of Ophthalmology, Faculty of Medicine, School of Health Sciences, University of Ioannina, Ioannina, Greece \\ ${ }^{2}$ Department of Medical Genetics and Clinical Embryology, Medical School, University of Ioannina, Ioannina, Greece \\ ${ }^{3}$ Laboratory of Medical Genetics in Clinical Practice, Medical School, University of Ioannina, Ioannina, Greece \\ ${ }^{4}$ Department of Ophthalmology, Faculty of Medicine, School of Health Sciences, University of Ioannina, Ioannina, Greece
}

\begin{abstract}
Background: Retinoblastoma is the most common primary intraocular malignancy in children, although it is a rare neural retinal tumor. Improving the quality of life is the next goal after the primary medical goal of life preservation. The genotypephenotype correlation may vary with the progression of retinoblastoma. Expressivity is determined by different $R B 1$ gene mutations among individuals. Herein, we share our experience on the evaluation of the long-term progression of retinoblastoma, its treatment consequences, its impact on the quality of life, and how the underlying genotypes are related to the phenotypes. We provide a review of the relevant literature and present a case of a sporadic heritable bilateral retinoblastoma.

Case Presentation: We report the outcomes of a 28-year follow-up of a female diagnosed with an infantile disease. The patient's best eye, according to the tumor classification and genetic results, was treated conservatively whereas the worst eye was enucleated. On re-examinations, she had complications of the treatment she received. Therefore, another intervention was administered for several years. The patient's pathogenic variant and RB1 gene mutational inactivation were predispositions to the recurrence of the tumor and non-ocular primary malignancy. Nevertheless, the disease had no progression. The patient is stable despite her type of retinoblastoma, which is the sporadic heritable bilateral form. Conclusions: Each phenotype of bilateral retinoblastoma varies in progression. The nature of the genetic mutation may determine its expressivity. It is of great significance to individualize every decision. In each case, the sequelae of the disease and treatment-induced complications may have an impact on the quality of the patient's life.
\end{abstract}

\section{KEY WORDS}

bilateral retinoblastoma, sporadic heritable retinoblastoma, RB1 gene, genotype-phenotype correlation, prognosis, intraocular malignancy, quality of life, genetic mutation, infantile retinoblastoma

Copyright (c) 2020, Author(s). This is an open-access article distributed under the terms of the Creative Commons Attribution-Non Commercial 4.0 International License (http://creativecommons.org/licenses/by-nc/4.o/) which permits copy and redistribute the material just in noncommercial usages, provided the original work is properly cited.

Correspondence to: Dr. Evita Evangelia Christou MD PhDc, Department of Ophthalmology, Faculty of Medicine, School of Health Sciences, University of Ioannina, Ioannina, Greece, E-mail: evitachristou@gmail.com

How to cite this article: Evangelia Christou E, Georgiou I, Kostoulas C, Batsos G, Christodoulou E, Stefaniotou M, Living with satisfactory vision and no comorbidity 28 years after bilateral retinoblastoma: a case report and mini literature review. Med Hypothesis Discov Innov Ophthalmol. 2020 Winter; 9(4): 264-272, DOI: https://doi.org/10.51329/mehdiophthal1412 


\section{INTRODUCTION}

Retinoblastoma $(\mathrm{Rb})$ is a rare neural retinal tumor $(-1: 15-$ 20.000 live births), probably arising from the cone precursor cells. It is the most common primary intraocular malignancy in children. The proportion of pediatric cancers is $17 \%$ in neonates [1], $13 \%$ in infants [2], and $6 \%$ and $3 \%$ during the $5^{\text {th }}$ and $15^{\text {th }}$ years, respectively $[3,4]$. The genetic mechanism underlying $\mathrm{Rb}$ represent an interesting example of the genetic underpinning of cancer. It correlates with mutations to the tumor suppressor gene $R B 1$, and in respect to the type of the first mutation it can result in distinct presentations. These include hereditary germline or non-hereditary somatic $\mathrm{Rb}$ based on family history, laterality at presentation, and current genetic tests [5]. Continuous progress in diagnosis and treatment methods has contributed to the 5-year disease-free survival rate of $\mathrm{Rb}$, which is the highest rate for a pediatric cancer. The preservation of ocular function and vision seems to be achieved in more than $97 \%$ of highincome countries and specialized centers $[4,6,7]$. Nevertheless, survival rates are much lower in the developing world, as was the case within the previous decades. Of bilaterally affected children, $96 \%$ had their worst eye enucleated during the irradiation era, with total blindness due to treatment failure occurring in $25-29 \%$ [ 8 , 9]; 64-66\% had their worst eye enucleated during the era of systemic chemotherapy, with total blindness in 2-6\% [9, 10]; less than $8 \%$ had their worst eye enucleated during the targeted chemotherapy era in cases with advanced disease [11]. The approach to treatment management may be highly individualized, and a collaboration of specialists is of great significance.

Here, we present a case of a woman with a sporadic heritable bilateral $\mathrm{Rb}$ diagnosed during infancy and followed up for 28 years. We aim to discuss the type of $R b$ and evaluate its long-term impact on the quality of life. We will also investigate the mutational pathogenic variability and penetrance of the disease and the relationship between its underlying genotypes and its phenotypes. We further highlight the predispositions to an increased risk of recurrence or second primary malignancies and the available therapeutic modalities.

\section{CASE PRESENTATION}

A seven-month-old female infant was presented to the pediatrician due to the clinical presentation of gazedependent leukocoria. The sign was identified during different gazes in the left eye, while it was intermittent and not visible during a straight gaze but only from the temporal side of the right eye. Therefore, the patient was immediately referred to an ophthalmologist and, in turn, a pediatric oncologist, she was subsequently diagnosed with infantile bilateral $\mathrm{Rb}$.

Tumor classification was used to evaluate the extent of the disease and determine the treatment approach, prognosis of eye preservation, and patient survival. The tumor staging was based on the usual classification systems that have been used for almost three decades (1992), as follows. According to the Reese and Ellsworth classification, the right eye was classified as IVa (multiple tumors larger than 10 disc diameter [DD] - unfavorable for preserving the eye), and the left eye was classified as Va (tumors involving more than half of the retina - very unfavorable for preserving the eye) [12]. According to the Essen classification, the right eye was classified as Ila (moderate-sized tumors of 8-10 DD, if not belonging to groups III-V for other reasons - favorable likelihood of globe salvage), and the left eye was classified as IVb (large tumors adjacent to or overlapping the optic disc unfavorable likelihood of globe salvage) [13]. Magnetic resonance imaging (MRI) of the brain and orbits ruled out any extraocular or central nervous system involvement. Further examination revealed no metastatic spread to the regional nodes, lungs, brain, and bones.

Genetic testing indicated a mutation in the tumor suppressor gene RB1 (NM_000321.2) and c.1959dupA (p.Val654Serfs $\left.{ }^{*} 14\right)$, which were pathogenic. Genetic examinations of the patient's family members were performed. Relatives with the disease, heterozygosity for an oncogenic $R B 1$ allele, or the clinical presence of Rbassociated eye lesions, such as retinomas, calcified retinal scars, or phthisis, were not found. Consequently, our case resulted from a de novo prezygotic germline mutation in the gametes of one of the healthy parents of the patient, which led to the mutational inactivation of the $R B 1$ gene. Thus, the Rb was classified as a sporadic/isolated heritable form. The therapeutic approach to the disease was demonstrated in a specialized center in Hospital Ophtalmique Jules Gonin, Lausanne, Switzerland, on October 30, 1992. The patient received the appropriate treatments according to the protocol at that time. Conservative treatment was administered in the right eye, which was the best eye. It included brachytherapy with a radioactive cobalt plaque $(15 \mathrm{~mm})$ and simultaneous cryotherapy for the pre-equatorial mass applied to the nasal side of the retina at the location of the tumor. Enucleation was performed in the left eye, which was the worst eye at diagnosis. Histological examination indicated a moderately differentiated type of $\mathrm{Rb}$. It demonstrated an exophytic growth pattern towards the subretinal space, which led to retinal detachment. There was no tumor invasion of the optic nerve, choroid, or vitreous body. The ophthalmological follow-up of our patient lasted for 28 years. Within the first year of her life, immediate 
supplementary treatment was administered because of a suspicious whitish region within the equatorial region. Subsequent examinations showed treatment-induced complications that lasted for several years, and they were mainly associated with the irradiated part of the retina; they consisted of radiation-related sectoral maculopathy and retinopathy, including proliferative neovascularization with consequent vitreous hemorrhage. A subcapsular cataract formation was observed. The dysfunctions of the lacrimal gland and nasolacrimal duct were observed after the initial treatment. Therefore, the patient underwent further topical and systemic therapy. These therapeutic modalities included cryotherapy and xenon photocoagulation, and they were repeated based on the outcomes. The multiple topical interventions facilitated a recession and the inactivation of the retinopathy, and chorioretinal atrophy occurred within the treated area. A subcapsular cataract obstructing the optical axis, which reduced the visual acuity, interfered with the examination of the fundus, and negatively impacted the quality of life for the patient, was observed. Because $\mathrm{Rb}$ active lesions were not suspected, cataract surgery was performed in Hospital Ophtalmique Jules Gonin, Lausanne, Switzerland on July 03, 2006 during the disease-free followup at the age of 14 years according to the protocol. She underwent phacoemulsification with posterior chamber intraocular lens implantation under general anesthesia. The posterior capsule remained intact. The postoperative treatment regimens included antibiotics, corticosteroids, and non-steroidal anti-inflammatory medications for two months. The posterior capsule, which was left intact, eventually became opacified, and she underwent neodymium (Nd): YAG laser capsulotomy approximately a year later. Some weeks later, her vision decreased due to cystoid macular edema compatible with the Irvine-Gass syndrome. Optical coherence tomography (OCT) revealed cystoid macular edema, and it confirmed the diagnosis (Figure 1). There was an intermittent relapse within the following two years, despite the topical and systemic pharmaceutical treatment. She received long-term treatment with high-dose oral acetazolamide: 250mg acetazolamide tablets three times daily for 12 months, followed by $125 \mathrm{mg}$ three times daily for 8 months and 125 mg twice daily for the last 8 months. Potassium gluconate was also administered to prevent the potential side effects of the medication. Our patient suffered from adverse effects of the ongoing therapy, which mainly included recurrent episodes of headache and dizziness accompanied by a feeling of depression that affected her quality of life. There were also intermittent anterior chamber angle closure and intraocular pressure elevation, which were managed accordingly. The treatment-induced complications lasted till she was 17 years old.
After the recession of the complications, the patient was stable until the recent regular ophthalmological examination. On examination of the right eye, the anterior segment was quiescent; a dilated vascular network located nasally corresponded to the irradiated tumor area. The posterior segment was also quiescent, with chorioretinal atrophy corresponding to the treated area (Figure 2). The confrontational test showed a limitation of the temporal visual field, although the patient did not cooperate during automated visual field examination. The best-corrected distance visual acuity was $20 / 25$ on the Snellen chart. In the left socket, there was an esthetically and anatomically well-preserved ocular prosthesis.

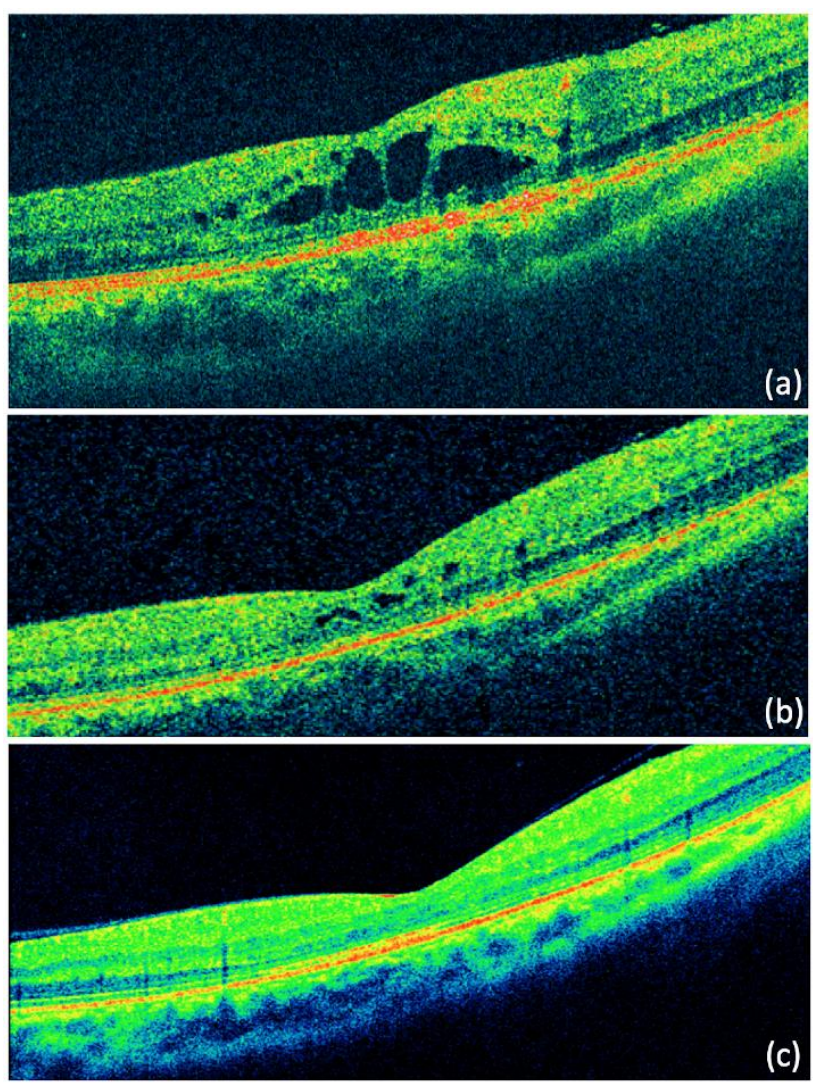

Figure 1: Right-eye Optical Coherence Tomography (OCT) examination revealed cystoid macular edema compatible with Irvine-Gass syndrome. The patient was treated with oral acetazolamide at the age of 15 years (a). The cystic spaces gradually diminished after two years of treatment (b). No evidence of cystic spaces was observed three years after the diagnosis (c). 

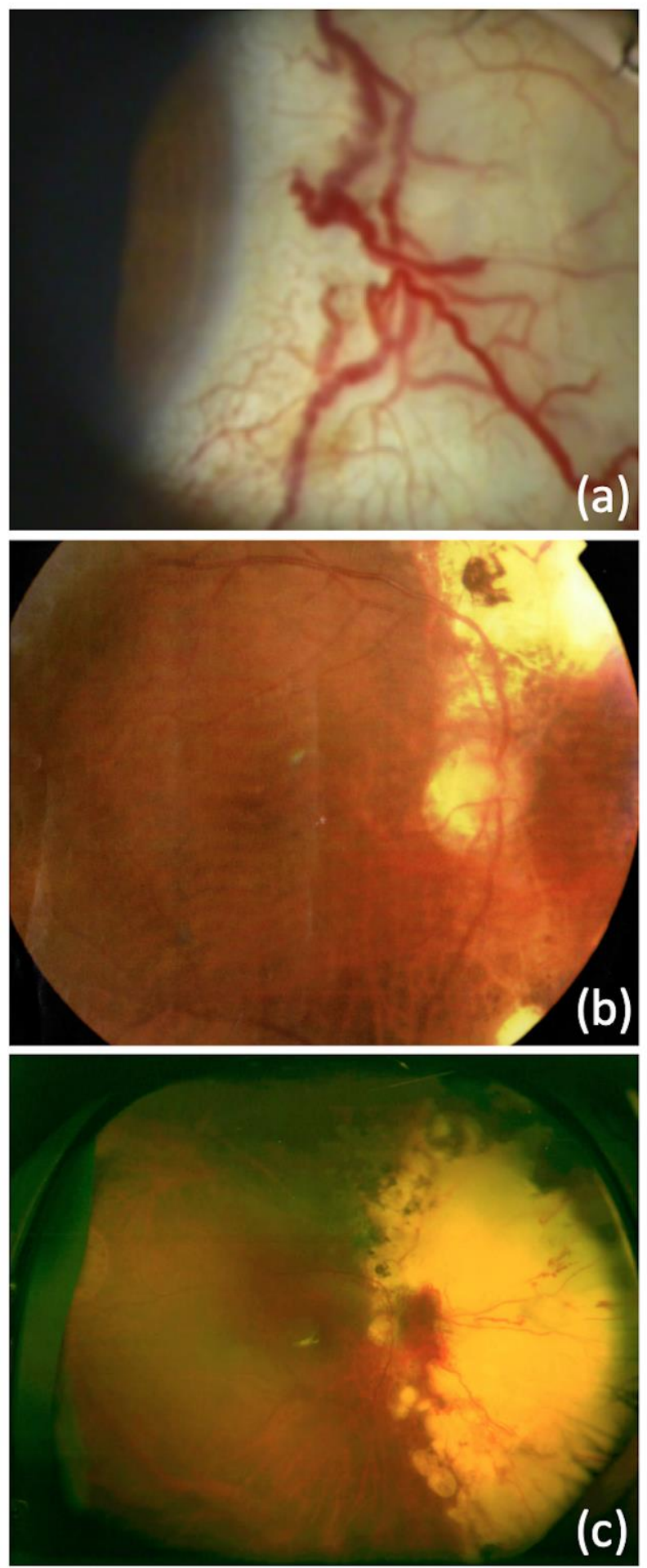

Figure 2: Anterior and posterior segment examination of the right eye at the age of 25 years. The dilated conjunctival vascular network in the nasal region of the anterior segment, corresponding to the irradiated tumor area, is notable (a). Radiation-related sectoral maculopathy (b) and retinopathy (c) can be observed in the color fundus photos. The nasal chorioretinal atrophy corresponds to the treated area.
Our patient and her family have been advised on the estimated risks of recurrence of the malignancy and possible risk of non-ocular or non-retinoblastoma malignancies later in life. They have been educated on the common signs of these conditions, to facilitate the prompt report of any suspicious symptoms, complimentary screening, and early diagnosis. The patient was further advised on the possibility of tumor development in her offspring and her options for avoiding the transmission. Table 1 summarizes the studies used for retinoblastoma management. Our case presentation was conducted in accordance with the ethical standards declared in the Declaration of Helsinki and was approved by the institutional review board. Data were collected to ensure Ethics Committee approval. Furthremore, we received a signed informed consent from the patient.

\section{DISCUSSION}

Our patient was diagnosed with the sporadic heritable bilateral form of $\mathrm{Rb}$ during infancy. Following the tumor classification and genetic results, she underwent conservative treatment in one eye and enucleation in the other. The classification staging systems and therapeutic modalities that were used may be considered obsolete in current practice. Our patient underwent a long-term followup for 28 years. Although she presented with treatmentinduced complications, treatment was continued for several years, and she maintained a satisfactory visual acuity. Genetic analysis revealed a pathogenic variant and RB1 gene mutational inactivation that predisposed her to tumor recurrence and a non-ocular primary malignancy. However, there has been no progression of the disease until today. Our patient was stable despite the type of $\mathrm{Rb}$.

$\mathrm{Rb}$ may be metastatic and potentially lethal if left untreated. The therapeutic approach aims to preserve life primarily; ocular survival, visual preservation, and quality of life are secondary targets [14]. The diagnosis, treatment, and monitoring of the patient involved the collaboration between various specialists, including ophthalmologists, pediatric oncologists, geneticists, related health personnel, and parents. It is of great significance that treatment is individualized [14]. Based on the two-hit hypothesis by Knudson, hereditary germline $\mathrm{Rb}$ is caused by two mutational events that target a gene on chromosome $13 q[15,16]$. RB1 was identified as the target of the mutational inactivation. The alterations are targeted at two alleles of the autosomal gene locus, and bi-allelic inactivation may be sufficient for $\mathrm{Rb}$ genesis $[17,18]$. Although in some cases, tumors may develop with biallelic $R B 1$ loss as the sole genomic alteration, recent studies have demonstrated recurrent chromosomal changes in several cases $[19,20]$. 
Table. Studies on retinoblastoma (Rb) management: gene mutational variability, potential risk of further malignancies, and treatment modalities.

\begin{tabular}{|c|c|c|}
\hline $\begin{array}{l}\text { First author, publication date, and } \\
\text { Study design }\end{array}$ & Short description & Outcomes of the study \\
\hline $\begin{array}{l}\text { Munier FL. et al (2019), [14] } \\
\text { Review }\end{array}$ & $\begin{array}{l}\text { Description of the conservative management of } \\
\text { retinoblastoma with considerations of potential } \\
\text { metastasis, retinoblastoma genesis, mutational } \\
\text { variabilities, imaging diagnostic modalities, disease and } \\
\text { treatment-induced complications, new therapeutic } \\
\text { targets, and concepts. }\end{array}$ & $\begin{array}{l}\text { The advent of new therapeutic techniques } \\
\text { facilitates eye salvage and a better quality of life. }\end{array}$ \\
\hline $\begin{array}{l}\text { Corson TW. et al (2007), [19] } \\
\text { Review }\end{array}$ & $\begin{array}{l}\text { Mutational events and loss of both alleles in the tumor } \\
\text { suppressor gene } R B 1 \text { are necessary for the initiation and } \\
\text { progression of retinoblastoma. The association between } \\
\text { genomic changes and clinical parameters should be } \\
\text { considered. Genes showing genomic changes are more } \\
\text { stable markers and potential therapeutic targets than } \\
\text { genes that are simply differentially expressed. }\end{array}$ & $\begin{array}{l}\text { Genomic changes in a molecular cytogenetic } \\
\text { pathway are critical in the development of } \\
\text { retinoblastoma. } \\
\text { The evaluation of cancer genes has diagnostic, } \\
\text { prognostic, and therapeutic implications. }\end{array}$ \\
\hline $\begin{array}{l}\text { Lohmann DR. et al (2004), [21] } \\
\text { Review }\end{array}$ & $\begin{array}{l}\text { Analysis of genotype-phenotype correlation and variability } \\
\text { in expression of features. }\end{array}$ & $\begin{array}{l}\text { The relationship between genotype and phenotypic } \\
\text { expression in hereditary retinoblastoma varies. }\end{array}$ \\
\hline $\begin{array}{l}\text { Hung CC. et al (2011), [22] } \\
\text { Study of } 30 \text { individuals from one } \\
\text { family }\end{array}$ & $\begin{array}{l}\text { Assessment of a mutation of the } R B 1 \text { gene associated with } \\
\text { low penetrance retinoblastoma within a family. }\end{array}$ & $\begin{array}{l}\text { Evaluation of various mutations may indicate the } \\
\text { penetrance of the disease. }\end{array}$ \\
\hline $\begin{array}{l}\text { Taylor M. et al (2007), [ } 23 \text { ] } \\
\text { Study of } 50 \text { pedigrees ( } 165 \text { carriers } \\
\text { of } R B 1 \text { mutation) }\end{array}$ & $\begin{array}{l}\text { A study of patients with a family history of retinoblastoma } \\
\text { and the spectrum of } R B 1 \text { germline mutations. }\end{array}$ & $\begin{array}{l}\text { Description of genotype-phenotype correlations in } \\
\text { hereditary familial retinoblastoma. Modifiable } \\
\text { factors may affect the pRB pathway regulation. }\end{array}$ \\
\hline $\begin{array}{l}\text { Abramson DH. et al (2001), [24] } \\
\text { Study of } 1,506 \text { patients (211 } \\
\text { second-tumor patients) }\end{array}$ & $\begin{array}{l}\text { Incidence, timing, pattern, distribution, and survival as a } \\
\text { result of more non-ocular primary tumors in survivors of } \\
\text { retinoblastoma. }\end{array}$ & $\begin{array}{l}\text { Retinoblastoma patients who have survived a } \\
\text { second malignancy are at higher risk of additional } \\
\text { tumors. The locations and expected age at which } \\
\text { new tumors develop are consistent with the } \\
\text { patterns from the previous condition of the patient. }\end{array}$ \\
\hline $\begin{array}{l}\text { Kleinerman RA. et al (2012), [ } 25] \\
\text { Study of 1,852 1-year survivors of } \\
\text { retinoblastoma }\end{array}$ & $\begin{array}{l}\text { Assessment of the variation of the second cancer risk with } \\
\text { the family history of retinoblastoma. Evaluation of the risk } \\
\text { of second cancer in long-term survivors of retinoblastoma } \\
\text { according to the classification of germline mutation and } \\
\text { based on family history of } \mathrm{Rb} \text { and laterality. }\end{array}$ & $\begin{array}{l}\text { An inherited germline mutation with bilateral } \\
\text { disease is associated with a greater predisposition } \\
\text { to a second malignancy compared with the de novo } \\
\text { germline mutation. Shared genetic alterations } \\
\text { should be considered. }\end{array}$ \\
\hline
\end{tabular}

Based on the timing of the two mutational events required to alter both $R B 1$ alleles, $\mathrm{Rb}$ is divided into heritable and non-heritable forms. Thus, $\mathrm{Rb}$ can be classified into four genetic forms. These include the inherited heritable/familiar form, isolated heritable form, mosaic form, and the non-heritable somatic form [5]. The heritable form, either familiar or isolated, is caused by germline genetic alterations. Typically, both oncogenic alleles identified from de novo mutations or familiar $\mathrm{Rb}$ with complete penetrance result in absent or disrupted pRB protein functions [21]. Loss-of-function variants in $R B 1$ are known to be pathogenic. Individuals with heritable forms are heterozygous for an oncogenic RB1 allele throughout their body; thus, the first mutation is present in all cells. An additional genetic alteration targeting the other $R B 1$ allele during retinal development is the second mutation that may initiate $\mathrm{Rb}$ genesis. Expressivity varies with the type of mutation at the first or the second allele. The nature of the mutation at the first allele determines the complete or incomplete penetrance. The number of mutations in the second allele affects the tumor extent. In sporadic heritable $\mathrm{Rb}$, the expression may or may not be attenuated, depending on the first mutation. Cases with de novo mutations result in oncogenic variants that are indistinguishable from familiar cases with complete penetrance (full expressivity). The majority of patients with bilateral $\mathrm{Rb}(95 \%)$ have germline $R B 1$ mutations and are heterozygous for an oncogenic RB1 allele that leads to pRB protein function loss, while the remaining $5 \%$ of the cases may be attributed to low-level mosaicism [21]. Due to its high penetrance, heritable $\mathrm{Rb}$ may be highly expressive. However, in some cases, low penetrance of $R B 1$ mutations has been reported, resulting in reduced expressivity. Incomplete penetrance is associated with genetic alterations that probably retain some of the pRB protein functions or affect the regulation of transcription of this gene [21]. Speculative explanations of the penetrance of $R b$ suggest that the incidence of somatic mutation, combination, and non-disjunction affect the retention of the residual normal allele in all retinal cells in carriers of germline mutations $[22,23,26$, 27]. Patients with a genomic 13q14 deletion have reduced expressivity, and those with large interstitial $13 q$ deletions show incomplete developmental phenotypes [28]. 
Although the underlying molecular mechanisms in cases of heritable $\mathrm{Rb}$ with low penetrance and variable expressivity are not well understood, mutation identification permits a more accurate estimation of the outcomes. The investigations of the mechanisms underlying the phenotypic expressions may include the investigation of variant $R B 1$ alleles associated with a low penetrance phenotype. The clinical assessment and molecular analysis indicate the phenotype and penetrance of $R B 1$ mutations in individuals. Research has shown that variable phenotypes can result from several factors, including modifier genes, allelic variation, and complex genetic and environmental interactions. Genetic epistasis is hypothesized to be an important factor in the development and progression of cancer and is widespread among cancer genes. Cancer is a consequence of the accumulation of mutations that may act epistatically during the disease. However, the determination of the combinations of genetic alterations that may interact to produce a specific phenotype remains a challenge. The genotype at one locus may affect the expression of alleles at another locus, and this interaction may occur between non-allelic genes. By assessing gene pairs and evaluating mutational profiling, it has been indicated that genetic interaction mapping may facilitate the personalization of treatment and the prediction of outcomes [29]. In our case, the sequence change that was detected in the RB1 gene is known to create a premature translational stop signal (p.Val654Serfs"14). This variant has been reported in individuals with bilateral $\mathrm{Rb}$ in the Leiden Open-source Variation Database [30], and it has been classified as pathogenic. This is expected to result in an absent or disrupted protein product. Evaluating the phenotype, we consider that expressivity is associated with the penetrance of the germline mutation of the RB1 gene. Epistasis with protective genes may have occurred during the disease. The genotype-phenotype correlation was determined based on the specific mutation, and it may be used to differentiate individuals with various mutations [21].

In cases with a positive family history of the disease, early screening for $\mathrm{Rb}$ is recommended. Before the use of modern imaging techniques and genetic testing, diagnostic screening was performed postnatally with indirect ophthalmoscopy [31]. Currently, for families with a known mutation, $R B 1$ mutational testing with DNA analysis may be carried prenatally during pregnancy using chorionic villus sampling or amniocentesis [32]. Genetic counseling depends on the presentation and the type of $\mathrm{Rb}$. Genetic alterations, allelic heterogeneity, variability in penetrance, and heritability of the background may dictate separate approaches to counseling [33]. In isolated heritable cases, the recurrence risk for siblings is $2 \%$ and even lower in other family members. The overall probability of transmission in the offspring of a patient in these cases is less than $50 \%$ due to possible somatic mutational mosaicism [34]. In our case, genetic counseling was provided to the parents, and genetic examinations were carried out. Heterozygosity or mutational inactivation of an oncogenic RB1 allele was not indicated; thus, the case was considered to be sporadically heritable. Our patient has been advised on the risk of tumor development in her offspring and her options for avoiding transmission by prenatal and preimplantation diagnosis. The screening schedule that was proposed in the current case for her future family planning was as follows: DNA extraction for mutational testing either by preimplantation genetic diagnosis or chorionic villus sampling at the end of the first trimester or amniocentesis during the second trimester of pregnancy. She was informed of the potential miscarriage risk for both procedures. Our patient was counseled for her condition during the early years of her diagnosis. She was informed of the prospects during her follow-up and advised by various specialists, such as geneticists, ophthalmologists, oncologists, and psychiatrists.

Due to the mutations in all cells in heritable cases, the majority of children develop bilateral and multifocal tumors usually within the first years of life, mainly during the first stage. The prevalence of sporadic $R b$ in these cases is $10 \%$ during the neonatal period [35]; it is generally diagnosed under 3 years, rare after 8 years, and typically not found after the age of 15 years [36-38]. The size of a gene deletion tends to correlate with the aggressiveness of $\mathrm{Rb}$. $\mathrm{Rb}$ patients carrying a germline $R B 1$ mutation have a lifetime risk of developing various types of primary malignancies, which further increases after external beam irradiation and chemotherapy [24,39]. This condition is associated with a predisposition to non-ocular tumors, such as pinealoblastoma, osteosarcoma, soft tissue sarcoma, and melanoma. The prevalence of secondary malignancies differs among various age groups [40-42]. Additionally, the carriers of inherited germline mutations have a slightly higher risk than those with a de novo germline mutation [25], which may be attributed to reduced penetrance or mosaicism [43]; in all these cases, primary nonretinoblastoma neoplasms may be the cause of mortality. In our case, the patient had no recurrence of malignancy until her last regular examination. Complimentary screening was performed, as indicated. The patient and family were educated on the increased risk and common signs of non-ocular or nonretinoblastoma malignancies which may develop in retinoblastoma survivor in later years.. Although the patient's type of $\mathrm{Rb}$ predisposed her to secondary 
neoplasms, she did not develop any during her 28-year follow-up.

Classification systems provide a universal basis for cancer management, particularly in $\mathrm{Rb}$. The diagnosis is clinical and there is no need for biopsy. In our case, the tumor staging was based on two separate classification systems introduced three decades ago (1992), although they are not currently used. The Reese and Ellsworth classification staging system grouped intraocular $\mathrm{Rb}$ into five for predicting eye survival in response to external beam radiotherapy for the affected eye, and not the likelihood of survival. It was the first system that considered the intraocular extent of the disease and was introduced in the 1960s [12, 44]. The Essen classification presented by Hopping was formulated based on newer evolving treatment modalities and showed a favorable correlation with globe salvage. This classification is difficult to apply in clinical practice and was therefore not used extensively [13]. The new systems are important for risk stratification and decision making and predictions of treatment success, including eye salvage and visual acuity preservation, and the development of a staging system to incorporate intraocular and extraocular diseases. The recently introduced Tumor, Node, Metastasis, and Heritability (TNMH) classification has been proposed to more accurately predict eye salvage, metastasis, and patient survival based on the intraocular, extraocular, and pathological manifestations of the disease and the hereditary status. It is likely to become the gold standard reference in the future [45]. It may provide a common foundation for evaluating the extent of disease and facilitate a more accurate and safe approach to patient management. The classification used to evaluate the disease extent and determine the treatment management and prognostication in our case differs from contemporary assessment systems. Our patient received the indicated treatment for almost three decades based on these systems.

New therapeutic modalities for the management of $\mathrm{Rb}$ have emerged over the last 20 years. Our patient received the indicated treatment based on the classification staging system used during that period. Until the recent introduction of new targeted treatment modalities, survival was achieved using disabling therapies. Historically, enucleation was the first successful therapeutic modality used to decrease mortality. Later, other methods that contributed to globe salvage, such as external beam radiotherapy, were used. Currently, there is an obvious preference for conservative treatment and less mutilating therapies. Conservative methods have been recommended as the treatment of choice for most cases. These include chemotherapy and intravenous or targeted modalities such as intra-arterial, intravitreal, or intracameral. The success of this technique lies in the selective delivery of high-dose drugs to the eye, with minimal systemic absorption. The well-defined genetic origin of $\mathrm{Rb}$ may indicate a potential gene therapy approach in the future. Research is ongoing in this field [14]. Nevertheless, the conservative treatment of retinoblastoma can be complicated by various conditions that are related to the disease or treatment, and if left untreated, they may compromise tumor management or globe preservation in eyes that were considered to be in remission [14]. In our case, the patient underwent enucleation of her worst eye, followed by conservative treatment of her best according to the protocol. In recent practice, this approach may be considered obsolete. She suffered from disease- and treatment-related complications for 17 years. Compared with the therapeutic approach used for this case, the contemporary treatment methodsmay be less invasive with a higher likelihood of eye preservation, better visual outcomes, and better quality of life.

The medical goal and primary target is to treat $\mathrm{Rb}$ and its potential disease- and treatment-induced complications. However, the overall quality of life and psychosocial consequences are particularly important. The risks of recurrence, non-ocular malignancies, further loss of vision, or having an affected offspring may negatively affect patients. The quality of life should be considered in all cases [14]. Our patient suffered comorbidities, emotional instability, and reduced quality of life until the recession of the complications at 17 years. Our patient has been regularly followed-up for 28 years. Despite the type of $\mathrm{Rb}$ diagnosis, she is alive with no comorbidities and a satisfying quality of life.

Since our case was initially diagnosed almost three decades ago, it was not possible to personally assess the diagnostic and therapeutic modalities that were used at that time. Approaches to similar cases in current practice differ, as contemporary methods are available. Although our presentation refers only to one case, our long-term examination and follow-up improve the understanding of the disease course and the various conditions that these patients suffer. However, our experience with the management and follow-up of recent cases is limited. Therefore, the findings from the current literature review provide a foundation for future prospective studies on $\mathrm{Rb}$ management. Future studies on the recent approaches to diagnosis and treatment and the long-term effects of $\mathrm{Rb}$ on patients' lives would be worthwhile. Further research should be carried out for these patients to achieve a better quality of life. 


\section{CONCLUSION}

$\mathrm{Rb}$ may be life-threatening if left untreated. The progress of each phenotype varied. Expressivity was determined based on the nature of the mutations. It is important for observation and treatment to be individualized, and the therapeutic approach to every patient will be the most suitable. The complications of the disease and adverse events of the treatment that the patient is administered may affect the quality of life.

\section{ETHICS DECLARATIONS}

Ethical approval: The study was conducted in accordance with the ethical standards of the Declaration of Helsinki. Data were collected to ensure Ethics Committee approval. The authores received a signed informed consent from the patient.

Conflict of interests: None

\section{FUNDING}

None

\section{ACKNOWLEDGEMENTS}

None

\section{REFERENCES}

1. Halperin EC. Neonatal neoplasms. Int J Radiat Oncol Biol Phys. 2000;47(1):171-8. doi: 10.1016/s0360-3016(00)004247 pmid: 10758320

2. Vasilatou-Kosmidis $\mathrm{H}$. Cancer in neonates and infants. Med Pediatr Oncol. 2003;41(1):7-9. doi: 10.1002/mpo.10153 pmid: 12764735

3. Broaddus $E$, Topham A, Singh AD. Incidence of retinoblastoma in the USA: 1975-2004. Br J Ophthalmol. 2009;93(1):21-3. doi: 10.1136/bjo.2008.138750 pmid: 18621794

4. Group AW, Ccm, Group AW. Italian cancer figures, report 2012: Cancer in children and adolescents. Epidemiol Prev. 2013;37(1 Suppl 1):1-225. pmid: 23585445

5. MacCarthy A, Birch JM, Draper GJ, Hungerford JL, Kingston $\mathrm{JE}$, Kroll ME, et al. Retinoblastoma: treatment and survival in Great Britain 1963 to 2002. Br J Ophthalmol. 2009;93(1):389. doi: 10.1136/bjo.2008.139626 pmid: 18838414

6. Fernandes AG, Pollock BD, Rabito FA. Retinoblastoma in the United States: A 40-Year Incidence and Survival Analysis. J Pediatr Ophthalmol Strabismus. 2018;55(3):182-8. doi: 10.3928/01913913-20171116-03 pmid: 29257183

7. Jenkinson H. Retinoblastoma: diagnosis and management-the UK perspective. Arch Dis Child. 2015;100(11):1070-5. doi: 10.1136/archdischild-2014-306208 pmid: 25940424

8. Abramson DH, Beaverson KL, Chang ST, Dunkel IJ, McCormick B. Outcome following initial external beam radiotherapy in patients with Reese-Ellsworth group $\mathrm{Vb}$ retinoblastoma. Arch Ophthalmol. 2004;122(9):1316-23. doi: 10.1001/archopht.122.9.1316 pmid: 15364710

9. Epstein JA, Shields CL, Shields JA. Trends in the management of retinoblastoma: evaluation of 1,196 consecutive eyes during 1974 to 2001. J Pediatr Ophthalmol Strabismus. 2003;40(4):196-203; quiz 17-8. pmid: 12908530

10. Kim H, Lee JW, Kang HJ, Park HJ, Kim YY, Shin HY, et al. Clinical results of chemotherapy based treatment in retinoblastoma patients: a single center experience. Cancer Res Treat. 2008;40(4):164-71. doi: 10.4143/crt.2008.40.4.164 pmid: 19688125

11. Francis JH, Roosipu N, Levin AM, Brodie SE, Dunkel IJ, Gobin YP, et al. Current Treatment of Bilateral Retinoblastoma: The Impact of Intraarterial and Intravitreous Chemotherapy. Neoplasia. 2018;20(8):757-63. doi: 10.1016/j.neo.2018.05.007 pmid: 29940303

12. Reese $A B$, Ellsworth RM. The evaluation and current concept of retinoblastoma therapy. Trans Am Acad Ophthalmol Otolaryngol. 1963;67:164-72. pmid: 13973597

13. de Sutter E, Havers W, Hopping W, Zeller G, Alberti W. The prognosis of retinoblastoma in terms of survival. A computer assisted study. Part II. Ophthalmic Paediatr Genet. 1987;8(2):85-8. doi: 10.3109/13816818709028522 pmid: 3658342

14. Munier FL, Beck-Popovic M, Chantada GL, Cobrinik D, Kivela TT, Lohmann D, et al. Conservative management of retinoblastoma: Challenging orthodoxy without compromising the state of metastatic grace. "Alive, with good vision and no comorbidity". Prog Retin Eye Res. 2019;73:100764. doi: 10.1016/j.preteyeres.2019.05.005 pmid: 31173880

15. Knudson AG, Jr. Mutation and cancer: statistical study of retinoblastoma. Proc Natl Acad Sci U S A. 1971;68(4):820-3. doi: $10.1073 /$ pnas.68.4.820 pmid: 5279523

16. Cavenee WK, Dryja TP, Phillips RA, Benedict WF, Godbout R, Gallie $B L$, et al. Expression of recessive alleles by chromosomal mechanisms in retinoblastoma. Nature. 1983;305(5937):779-84. doi: 10.1038/305779a0 pmid: 6633649

17. Grobner SN, Worst BC, Weischenfeldt J, Buchhalter I, Kleinheinz K, Rudneva VA, et al. The landscape of genomic alterations across childhood cancers. Nature. 2018;555(7696):321-7. doi: 10.1038/nature25480 pmid: 29489754

18. Zhang J, Benavente CA, McEvoy J, Flores-Otero J, Ding L, Chen $X$, et al. A novel retinoblastoma therapy from genomic and epigenetic analyses. Nature. 2012;481(7381):329-34. doi: 10.1038/nature10733 pmid: 22237022

19. Corson TW, Gallie BL. One hit, two hits, three hits, more? Genomic changes in the development of retinoblastoma. Genes Chromosomes Cancer. 2007;46(7):617-34. doi: 10.1002/gcc.20457 pmid: 17437278

20. Kooi IE, Mol BM, Massink MP, de Jong MC, de Graaf $P$, van der Valk $P$, et al. A Meta-Analysis of Retinoblastoma Copy Numbers Refines the List of Possible Driver Genes Involved in Tumor Progression. PLoS One. 2016;11(4):e0153323. doi: 10.1371/journal.pone.0153323 pmid: 27115612 
21. Lohmann DR, Gallie BL. Retinoblastoma: revisiting the model prototype of inherited cancer. Am J Med Genet C Semin Med Genet. 2004;129C(1):23-8. doi: 10.1002/ajmg.c.30024 pmid: 15264269

22. Hung CC, Lin SY, Lee CN, Chen CP, Lin SP, Chao MC, et al. Low penetrance of retinoblastoma for p.V654L mutation of the RB1 gene. BMC Med Genet. 2011;12:76. doi: 10.1186/14712350-12-76 pmid: 21615945

23. Taylor M, Dehainault C, Desjardins L, Doz F, Levy C, Sastre X, et al. Genotype-phenotype correlations in hereditary familial retinoblastoma. Hum Mutat. 2007;28(3):284-93. doi: 10.1002/humu.20443 pmid: 17096365

24. Abramson DH, Melson MR, Dunkel IJ, Frank CM. Third (fourth and fifth) nonocular tumors in survivors of retinoblastoma. Ophthalmology. 2001;108(10):1868-76. doi: 10.1016/s01616420(01)00713-8 pmid: 11581064

25. Kleinerman RA, Yu CL, Little MP, Li Y, Abramson D, Seddon J, et al. Variation of second cancer risk by family history of retinoblastoma among long-term survivors. J Clin Oncol. 2012;30(9):950-7. doi: 10.1200/JCO.2011.37.0239 pmid: 22355046

26. Alonso J, Frayle H, Menendez I, Lopez A, Garcia-Miguel P, Abelairas J, et al. Identification of 26 new constitutional RB1 gene mutations in Spanish, Colombian, and Cuban retinoblastoma patients. Hum Mutat. 2005;25(1):99. doi: 10.1002/humu.9299 pmid: 15605413

27. He MY, An Y, Gao YJ, Qian XW, Li G, Qian J. Screening of RB1 gene mutations in Chinese patients with retinoblastoma and preliminary exploration of genotype-phenotype correlations. Mol Vis. 2014;20:545-52. pmid: 24791139

28. Munier F, Pescia G, Jotterand-Bellomo M, Balmer A, Gailloud C, Thonney F. Constitutional karyotype in retinoblastoma. Case report and review of literature. Ophthalmic Paediatr Genet. 1989;10(2):129-50. doi: 10.3109/13816818909088353 pmid: 2674826

29. Wang X, Fu AQ, McNerney ME, White KP. Widespread genetic epistasis among cancer genes. Nat Commun. 2014;5:4828. doi: 10.1038/ncomms5828 pmid: 25407795

30. Fokkema IF, Taschner PE, Schaafsma GC, Celli J, Laros JF, den Dunnen JT. LOVD v.2.0: the next generation in gene variant databases. Hum Mutat. 2011;32(5):557-63. doi: 10.1002/humu.21438 pmid: 21520333

31. Abramson DH, Du TT, Beaverson KL. (Neonatal) retinoblastoma in the first month of life. Arch Ophthalmol. 2002;120(6):738-42. doi: 10.1001/archopht.120.6.738 pmid: 12049578

32. Akolekar R, Beta J, Picciarelli G, Ogilvie C, D'Antonio F. Procedure-related risk of miscarriage following amniocentesis and chorionic villus sampling: a systematic review and meta-analysis. Ultrasound Obstet Gynecol. 2015;45(1):16-26. doi: 10.1002/uog.14636 pmid: 25042845

33. Valverde JR, Alonso J, Palacios I, Pestana A. RB1 gene mutation up-date, a meta-analysis based on 932 reported mutations available in a searchable database. BMC Genet. 2005;6:53. doi: 10.1186/1471-2156-6-53 pmid: 16269091

34. Draper GJ, Sanders BM, Brownbill PA, Hawkins MM. Patterns of risk of hereditary retinoblastoma and applications to genetic counselling. $\mathrm{Br} J$ Cancer. 1992;66(1):211-9. doi: 10.1038/bjc.1992.244 pmid: 1637670

35. Kivela TT, Hadjistilianou T. Neonatal Retinoblastoma. Asia Pac J Oncol Nurs. 2017;4(3):197-204. doi: 10.4103/apjon.apjon_18_17 pmid: 28695165

36. Gatta G, Ferrari A, Stiller CA, Pastore G, Bisogno G, Trama A, et al. Embryonal cancers in Europe. Eur J Cancer. 2012;48(10):1425-33. doi: 10.1016/j.ejca.2011.12.027 pmid: 22357215

37. Park SJ, Woo SJ, Park KH. Incidence of retinoblastoma and survival rate of retinoblastoma patients in Korea using the Korean National Cancer Registry database (1993-2010). Invest Ophthalmol Vis Sci. 2014;55(5):2816-21. doi: 10.1167/iovs.14-14078 pmid: 24692122

38. Rangamani S, SathishKumar K, Manoharan N, Julka PK, Rath GK, Shanta V, et al. Paediatric retinoblastoma in India: evidence from the National Cancer Registry Programme. Asian Pac J Cancer Prev. 2015;16(10):4193-8. doi: 10.7314/apjcp.2015.16.10.4193 pmid: 26028071

39. Marees $T$, van Leeuwen FE, Schaapveld M, Imhof SM, de Boer MR, Kors WA, et al. Risk of third malignancies and death after a second malignancy in retinoblastoma survivors. Eur J Cancer. 2010;46(11):2052-8. doi: 10.1016/j.ejca.2010.03.029 pmid: 20400293

40. Abramson DH, Ronner HJ, Ellsworth RM. Second tumors in nonirradiated bilateral retinoblastoma. Am J Ophthalmol. 1979;87(5):624-7. doi: 10.1016/0002-9394(79)90293-9 pmid: 286550

41. Eng C, Li FP, Abramson DH, Ellsworth RM, Wong FL, Goldman $\mathrm{MB}$, et al. Mortality from second tumors among long-term survivors of retinoblastoma. J Natl Cancer Inst. 1993;85(14):1121-8. doi: 10.1093/jnci/85.14.1121 pmid: 8320741

42. Wong FL, Boice JD, Jr., Abramson DH, Tarone RE, Kleinerman RA, Stovall $M$, et al. Cancer incidence after retinoblastoma. Radiation dose and sarcoma risk. JAMA. 1997;278(15):12627. doi: 10.1001/jama.278.15.1262 pmid: 9333268

43. Moll AC, Dommering CJ, Bosscha MI, de Graaf P, Kors WA, van Leeuwen FE. Risk factors for the incidence of second cancers in survivors of retinoblastoma with a family history. J Clin Oncol. 2012;30(24):3028; author reply -9. doi: 10.1200/JCO.2012.43.7640 pmid: 22802309

44. de Sutter E, Havers W, Hopping W, Zeller G, Alberti W. The prognosis of retinoblastoma in terms of globe saving treatment. A computer assisted study. Part I. Ophthalmic Paediatr Genet. 1987;8(2):77-84. doi: 10.3109/13816818709028521 pmid: 3658341

45. Mallipatna A, Finger P. Retinoblastoma. In: Amin M, Edge S, Greene F, editors. AJCC Cancer Staging Manual. 8th ed. New York: Springer; 2017. p. 819-31. 